Full Paper

\title{
Influence of fermented soy protein consumption on hypertension and gut microbial modulation in spontaneous hypertensive rats
}

\author{
Eric Banan-Mwine DALIRI ${ }^{1}$, Fred Kwame OFOSU ${ }^{1}$, Ramachandran CHELLIAH ${ }^{1}$, Byong H. LEE ${ }^{4,5}$, \\ Hongyan AN ${ }^{5}$, Fazle ELAHI ${ }^{1}$, Kaliyan BARATHIKANNAN ${ }^{1}$, Joong-Hark $\mathrm{KIM}^{2,3}$ and Deog-Hwan $\mathrm{OH}^{{ }^{*}}$ \\ ${ }^{1}$ Department of Food Science and Biotechnology, Kangwon National University, Chuncheon 200-701, Korea \\ ${ }^{2} R \& D$, Erom Company Limited, R\&D Center, 111, Toegye Nonggong-ro, Chuncheon-si, Gangwon-do 24427, Korea \\ ${ }^{3}$ Department of Medical Biotechnology, College of Biomedical Sciences, Kangwon National University, Chuncheon, Gangwon-do 24341 , \\ Korea \\ ${ }^{4}$ Department of Microbiology/Immunology, McGill University, Montreal, QC, H3A 2B4, Canada \\ ${ }^{5}$ SportBiomics, Inc., Sacramento, CA, USA
}

Received January 6, 2020; Accepted April 19, 2020; Published online in J-STAGE May 14, 2020

\begin{abstract}
Plant proteins are known to possess important bioactive peptides and have a positive impact on gut microbial modulation. In this study, we studied the ability of a single dose of a fermented soy protein product (P-SPI) to reduce high blood pressure in spontaneous hypertensive rats (SHR) and how it modulates the gut microbiota after six weeks of feeding. SHRs were fed with P-SPI, Captopril or distilled water once, and their blood pressures were monitored from the first to twelfth-hour post-administration. Consumption of P-SPI significantly reduced systolic and diastolic blood pressures up to the sixth hour by $25 \pm 4 \mathrm{mmHg}$ and $40 \pm 5 \mathrm{mmHg}$ respectively. P-SPI consumption inhibited serum ACE activity, increased superoxide dismutase activity and nitric oxide levels and reduced malondialdehyde levels in serum. Analysis of fecal microbial 16S rRNA of hypertensive rats revealed a significant reduction in microbial richness and diversity in the gut, while P-SPI consumption improved microbial richness and increased diversity. Also, P-SPI feeding significantly reduced the Firmicutes/Bacteroidetes ratio, increased propionate- and $\mathrm{H}_{2} \mathrm{~S}$-producing bacteria and reduced Streptococcaceae and Erysipelotrichales levels. Our results show that P-SPI is a potential antihypertensive functional food which could remodel the altered gut microbiota of hypertensive patients.
\end{abstract}

Key words: bioactive peptides, functional foods, dysbiosis, next generation sequencing

\section{INTRODUCTION}

Hypertension is one of the modifiable risk factors for stroke, obesity, cardiovascular diseases and metabolic syndrome [1]. The prevalence of hypertension still remains high despite modification of lifestyle and recent improvements in pharmacotherapy [2]. Patients with treatment-resistant hypertension may eventually experience dysautonomia and chronic low-grade inflammation which may promote organ damage and sustained high blood pressure [2, 3]. Although many possible mechanisms of hypertension have been proposed over the years, the renin-angiotensin-aldosterone system (RAAS) has been most studied [4]. The rate-limiting step of the RAAS is controlled by angiotensin 1-converting enzyme (ACE), and this makes ACE a good drug target for blood pressure control [4]. Recent studies have also demonstrated how decreased gut microbial richness could be associated with hypertension [5] and lead to cardiovascular diseases and metabolic syndrome [6]. This is because the gut microbiota plays a pivotal role in shaping a healthy systemic and intestinal immune system [7, 8]. For this reason, many studies have investigated the link between the gut microbiota and hypertension $[9,10]$. For instance, the Coronary Artery Risk Development in Young Adults (CARDIA) study carried out in the USA showed a clear association between changes in faecal microbiota and hypertension. The study showed that Robinsoniella and Catabacter in faecal samples were strongly associated with hypertension [9]. In another study, hypertensive patients, relative to their normotensive counterparts, were found

*Corresponding author. Deog-Hwan Oh (E-mail: deoghwa@kangwon.ac.kr)

(Supplementary material: refer to PMC https://www.ncbi.nlm.nih.gov/pmc/journals/2480/)

(C2020 BMFH Press

This is an open-access article distributed under the terms of the Creative Commons Attribution Non-Commercial No Derivatives (by-nc-nd) License. (CC-BY-NC-ND 4.0: https://creativecommons.org/licenses/by-nc-nd/4.0/) 
to have significantly reduced levels of Roseburia spp. and Faecalibacterium prausnitzii (short-chain fatty acid producers), while Streptococcus spp. and Klebsiella spp. (opportunistic pathogens) were increased [10]. All these findings make the gut microbiota an attractive target for blood pressure control, and hence various strategies are being sought to reduce blood pressure and modulate the gut microbiota. Diet could alter the gut microbiota community and influence its function by modulating the metabolites it produces $[11,12]$. Therefore, many studies have focused on the impact of different foods (high-fat diets, vegetarian diets, low-fat diets, high-fiber diets, etc.) on the gut microbiota $[11,12]$. Also, several other studies have developed functional foods to be used as nonpharmacological treatments for high blood pressure [13]. Although these antihypertensive functional foods, apart from inhibiting angiotensin-converting enzyme (ACE) activity and/or reducing renin activity [4, 14], may have direct impacts on the gut microbiota, very few (if any) studies have assessed the effects of the foods on gut microbial modulation. In our previous study, we reported that long-term feeding of spontaneous hypertensive rats (SHRs) with a soy protein product (P-SPI) developed with bioconvergence technology significantly reduced systolic blood pressure [15]. In this study however, we investigated the impact of a single dose of P-SPI on high blood pressure and the effect of P-SPI on the faecal microbiota of the rats after feeding them for six weeks.

\section{MATERIALS AND METHODS}

\section{Sample preparation}

P-SPI was prepared as we reported earlier [15]. Briefly, $20 \%(\mathrm{w} / \mathrm{v})$ soybean protein isolates (ADM, Decatur, IL, USA) was hydrolyzed with Prozyme (Bison Corporation, Gyunggido, South Korea) according to the enzyme manufacturer's instructions. After hydrolysis, the hydrolysate was fermented with Lactobacillus rhamnosus EBD1 (Department of Food Science and Biotechnology, Kangwon National University, Chuncheonsi, Kangwon-do, South Korea) for $48 \mathrm{hr}$ at $37^{\circ} \mathrm{C}$. The fermentate was stored at $-80^{\circ} \mathrm{C}$ until it was needed for further experiments.

\section{Animal preparation}

All the animal experiments were carried out according to the ethical procedures and guidelines of the Kangwon National University-Institutional Animal Care and Use Committee (approval no. KW-151127-1). In all, forty male SHRs (12 weeks old) weighing 250-300 g were obtained from Charles River Laboratories, Barcelona, Spain, and used for the experiments. The SHRs were separated by simple randomization into four groups, kept in temperature-controlled rooms $\left(23^{\circ} \mathrm{C}\right)$ with $12 \mathrm{hr}$ light/dark cycles and provided with tap water and standard 5001 rodent laboratory chow (Purina, Saint Hubert, Quebec, Canada) ad libitum. Indirect blood pressure in awake restrained rats was measured by the non-invasive tail-cuff method using computerassisted non-invasive blood pressure equipment (NIBP 76-0173 unit with LE5160R cuff \& transducer, Sang Chung Commercial Co., Ltd, Kangnam-Ku, South Korea). To make the pulsations of the tail artery detectable, the rats were kept at $37^{\circ} \mathrm{C}$ for $15 \mathrm{~min}$.

\section{Blood pressure lowering effect of P-SPI in SHRs}

To study the impact of a single dose of P-SPI consumption on blood pressure, each group of hypertensive rats was either administered with $10 \mathrm{mg}$ of P-SPI per $\mathrm{kg}$ body weight (BW), $100 \mathrm{mg} / \mathrm{kg}$ of P-SPI per $\mathrm{kg} \mathrm{BW}, 50 \mathrm{mg} / \mathrm{kg} \mathrm{BW}$ of Captopril (Sigma-Aldrich, Yongin, South Korea) or $750 \mu \mathrm{L}$ distilled water once by gastric intubation. Systolic blood pressure (SBP) and diastolic blood pressure (DBP) were measured before P-SPI intake (time 0) and after intake every hour for the next $12 \mathrm{hr}$. To avoid stress during blood pressure measurements, the tail-cuff was deflated after each measurement. Each value of SBP and DBP was obtained by averaging five successful measurements without disturbance of the signal. After $12 \mathrm{hr}$ of treatment, five rats from each group were anesthetized using pentobarbital at an intraperitoneal dose of $60 \mathrm{mg} \mathrm{kg}^{-1}$ body weight, and the blood was extracted by cardiac puncture $(5 \mathrm{~mL}$ per rat) with a $5 \mathrm{~mL}$ $23 \mathrm{G}$ syringe. Serum was recovered from the blood and stored at $-80^{\circ} \mathrm{C}$ for further studies.

To study the impact of long-term feeding on SHRs, the remaining SHRs ( $\mathrm{n}=5$ rats per group) were continuously given their respective treatments (once a day) for six weeks, and their blood pressures were recorded once every two weeks.

\section{ACE inhibitory ability of P-SPI in SHR serum}

ACE inhibition in the serum of the rats used in the study was measured using a previously reported method [16]. HippurylL-histidyl-L-leucine was dissolved in $0.1 \mathrm{~mol} / \mathrm{L}$ sodium borate buffer $(\mathrm{pH} 8.3$ ) containing $0.3 \mathrm{~mol} / \mathrm{L} \mathrm{NaCl}$. The reaction was started by adding $100 \mu \mathrm{L}$ of the serum, and the mixture was incubated at $37^{\circ} \mathrm{C}$. After $30 \mathrm{~min}$, the reaction was stopped by adding $1 \mathrm{~mL}$ of $1 \mathrm{M} \mathrm{HCl}$. Hippuric acid (HA) liberated by the reaction was extracted using $1.0 \mathrm{~mL}$ ethyl acetate, vortexed for $60 \mathrm{sec}$ and centrifuged at 2,000 $\times \mathrm{g}$ for $5 \mathrm{~min}$. The ethyl acetate layer $(0.8 \mathrm{~mL})$ was transferred to a $1.5 \mathrm{~mL}$ Eppendorf tube and evaporated on a water bath. The HA in the tube was dissolved with distilled water $(0.8 \mathrm{~mL})$. The amount of HA formed was measured at $228 \mathrm{~nm}$ using a biospectrometer (Eppendorf Biospectrometer ${ }^{\circledR}$ fluorescence, Eppendorf Korea Ltd., Seoul, South Korea). One unit (U) of activity was defined as the amount of enzyme which released $1.0 \mathrm{mmol}$ of hippuric acid/min under the above conditions. The specific activity of ACE in serum was expressed as U/L.

\section{Estimation of serum nitric oxide (NO) after P-SPI consumption}

Serum NO concentration was determined by the Griess reaction with a colorimetric assay kit (BioVision, Inc., Milpitas, CA, USA). This assay was carried out according to the manufacturer's instructions. The concentration of NO in serum was expressed as $\mu \mathrm{mol} / \mathrm{L}$.

\section{Biomarkers of oxidative stress after P-SPI consumption}

\section{Superoxide dismutase (SOD) activity}

Determination of SOD activity in serum was performed using a superoxide dismutase assay kit (BioVision, Inc., Milpitas, CA, USA). The assay was carried out according to the manufacturer's instructions.

\section{Determination of lipid peroxidation}

The extent of lipid peroxidation in serum was determined using a Lipid Peroxidation Colorimetric Assay Kit (BioVision, Inc., Milpitas, CA, USA). The degree of lipid peroxidation 
was measured indirectly by determining the levels of malondialdehyde in serum. The assay was carried out according to the manufacturer's instructions.

\section{Long-term effects of P-SPI on the gut microbiota}

Using sterile plastic vials, fresh fecal samples were collected directly from the anus of the experimental rats after the six weeks of feeding with P-SPI and immediately stored at $-80^{\circ} \mathrm{C}$. Total bacterial DNA in the faecal samples was extracted using a Bacterial Genomic DNA Isolation Kit (BioVision, Inc., Milpitas, CA, USA) according to the manufacturer's protocols. The DNA was delivered to Macrogen Inc (Geuncheon-gu, Seoul, South Korea) for next generation sequencing.

\section{Next generation sequence (NGS)}

\section{Illumina next generation sequence workflow}

Next generation sequencing was carried out by Macrogen Inc (Geuncheon-gu, Seoul, South Korea). After subjecting the extracted DNA to quality control measures, qualified samples were used for library construction. The sequencing library was prepared by random fragmentation of the DNA or cDNA sample, followed by $5^{\prime}$ and $3^{\prime}$ adapter ligation. Adapter-ligated fragments were then amplified by polymerase chain reaction and purified by gel electrophoresis. For cluster generation, the library was loaded into a flow cell, where fragments were captured on a lawn of surface-bound oligos complementary to the library adapters. Each fragment was then amplified into unique clonal clusters through bridge amplification. Illumina SBS technology was used to generate accurate base-by-base sequencing. Sequencing data was converted into raw data for the analysis. The base calls binary was converted into FASTQ utilizing the illumina package bcl2fastq.

\section{NGS data analysis}

Effective reads from all samples were clustered into operational taxonomic units (OTUs), based on 97\% sequence similarity. Rarefaction analysis and principal coordinate analysis (PCoA) were performed using R software. Explicet version 2.10.5 [17] was used to calculate the Simpson's and Shannon's alpha diversity in the faecal samples from each group based on the relative abundance of each genus. To statistically compare the Simpson diversity between samples, the bootstrap sampling method was used. Community diversity between samples was determined using the UniFrac distance (weighted). Bray-Curtis dissimilarity was used to evaluate the diversity (gene richness) between samples.

\section{Statistical analysis}

Baseline blood pressure was defined as the mean of the values measured in the first run-in period. Blood pressure was presented as the mean value \pm standard deviations for all experimental animals in each group. The outcomes of measurements from each time period were compared between groups with one-way ANOVA followed by the Tukey test. Differences in measurements were said to be significant when $\mathrm{p}<0.05$. All statistical analyses were carried out using GraphPad Prism version 5.01 (GraphPad Software, Inc).

\section{RESULTS}

\section{Single oral dose of P-SPI reduces blood pressure in SHRs in a dose-dependent manner}

The mean SBP for all the hypertensive rats in the four experimental groups prior to treatment was $179 \pm 5.6 \mathrm{mmHg}$, and their mean DBP was $111.2 \pm 2.7(n=20)$. At the sixth hour, the single oral administration of Captopril reduced SBP to $144.7 \pm$ $3.7(\mathrm{p}<0.05)$, while $100 \mathrm{mg} / \mathrm{kg}$ P-SPI reduced SBP to $151.9 \pm 5.0$ $(\mathrm{p}<0.05)$; in both cases, the blood pressure subsequently began to rise (Fig. 1). Meanwhile, the blood pressure of hypertensive rats that received distilled water remained high $(175 \pm 5.0, \mathrm{p}>0.05)$ throughout the experimental period. The maximum blood pressure reduction in all the experimental groups was recorded at the sixth hour. Hypertensive rats that received $10 \mathrm{mg} / \mathrm{kg}$ P-SPI experienced a $22.2 \mathrm{mmHg}$ reduction in $\mathrm{SBP}$ and a $24.7 \mathrm{mmHg}$ reduction in DBP. Meanwhile, hypertensive rats that received $100 \mathrm{mg} / \mathrm{kg}$ P-SPI also experienced $27.1 \mathrm{mmHg}$ and $38.6 \mathrm{mmHg}$ reductions in SBP and DBP respectively. Captopril caused 34.3 $\mathrm{mmHg}$ and $34.2 \mathrm{mmHg}$ reductions in SBP and DBP respectively (Fig. 1).

\section{Single oral dose of P-SPI improves serum parameters associated with hypertension}

To assess the in vivo ACE inhibitory activity of P-SPI, we determined the ACE activity in the serum of treated and untreated rat groups (Fig. 2A). Serum ACE activity was significantly reduced in hypertensive rats treated with Captopril and P-SPI relative to untreated hypertensive rats. It is known that impaired NO production can lead to endothelial dysfunction and result in high blood pressure [18]. We therefore assessed the impact of P-SPI consumption on serum NO levels. After the treatments, serum NO concentrations were significantly $(\mathrm{p}<0.05)$ higher than in the untreated hypertensive rats (Fig. 2B). There was no significant $(\mathrm{p}>0.05)$ difference in the NO levels in rats that received $10 \mathrm{mg} / \mathrm{kg}$ P-SPI and the Captopril group. However, rats that received $100 \mathrm{mg} / \mathrm{kg}$ P-SPI had the highest levels of serum NO. SOD is an intracellular antioxidant system that modulates vascular remodeling and regulates blood pressure [19]. Treatment with either P-SPI or Captopril caused a significant increase in SOD activity (Fig. 2C). SOD activity in the Captopril group was not significantly different from that in the $100 \mathrm{mg} / \mathrm{kg}$ P-SPI group ( $p>0.05$ ). Untreated hypertensive rats, however, had the least SOD activity. It is known that hypertension is associated with an increased degree of lipid peroxidation [20], so we measured the levels of one of the products of lipid peroxidation, malondialdehyde (MDA), in rat serum. The levels of MDA products in the serum were used as an indicator for the degree of lipid peroxidation (Fig. 2D). It was observed that untreated SHRs showed the highest levels of MDA relative to the treated rats.

\section{Long term P-SPI consumption alters the gut microbial community of SHRs}

To assess the effects of long-term P-SPI consumption on the gut microbiota, we compared the faecal microbial communities in the untreated, P-SPI-treated (100 mg/kg body weight) and Captopril-treated rat groups.

We assessed the phylogenetic dispersion of the untreated SHR, Captopril and P-SPI groups using rarefaction curves. Phylogenetic dispersion $(\triangle \mathrm{PD})$ values were highest in the 
A

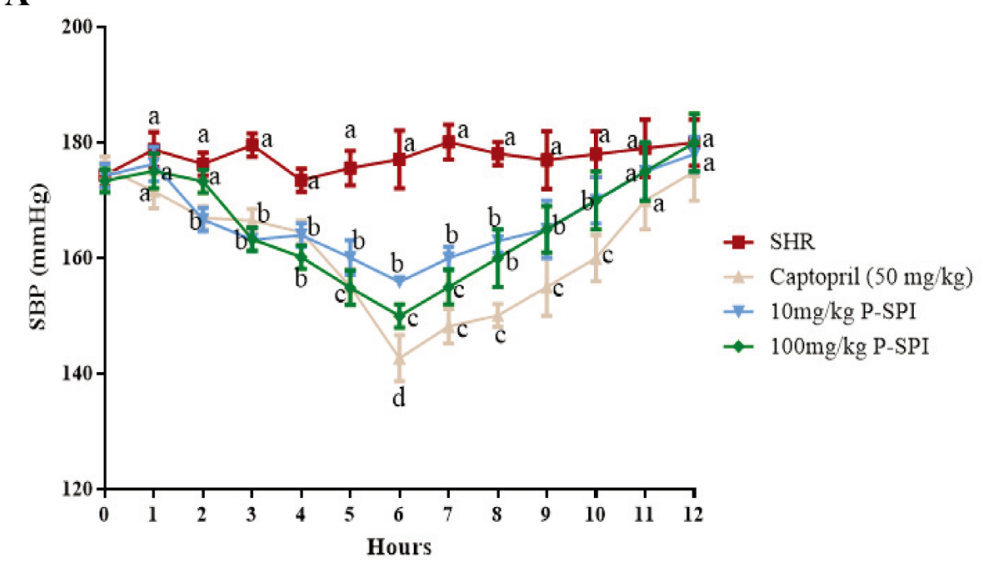

B

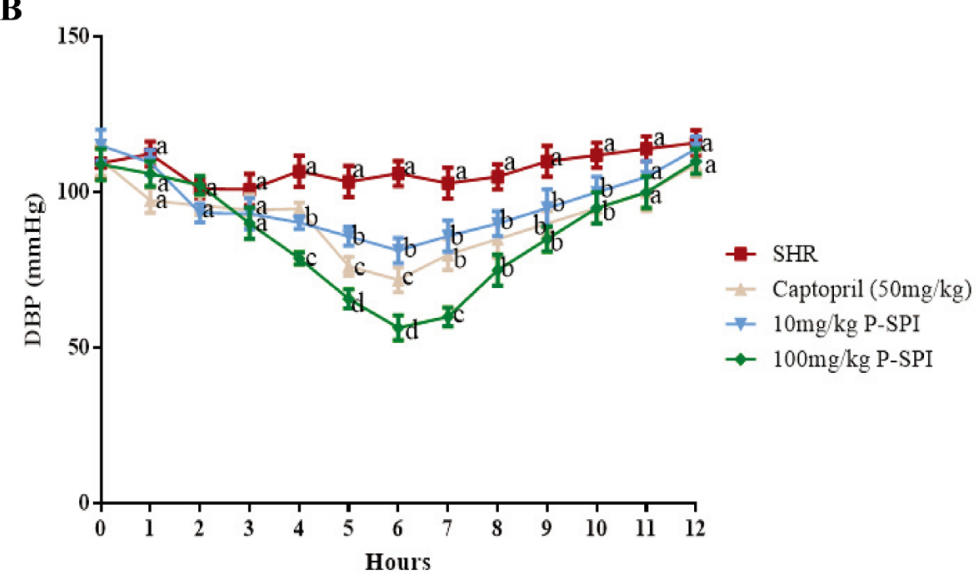

Fig. 1. Effects of single-dose oral administration of P-SPI on blood pressure in spontaneous hypertensive rats. (A) Systolic blood pressure of spontaneous hypertensive rats before and after treatment with $10 \mathrm{mg} / \mathrm{kg}$ P-SPI, $100 \mathrm{mg} /$ $\mathrm{kg}$ P-SPI or $50 \mathrm{mg} / \mathrm{kg}$ Captopril and (B) diastolic blood pressure of spontaneous hypertensive rats before and after treatment with $10 \mathrm{mg} / \mathrm{kg}$ P-SPI, $100 \mathrm{mg} / \mathrm{kg}$ P-SPI or $50 \mathrm{mg} / \mathrm{kg}$ Captopril. Data are presented as means $\pm \mathrm{SD}$. Data points sharing the same letter within the same hour were not significantly different $(p>0.05)$.

Captopril group and lowest in the untreated SHR group (Fig. 3A). Bacteria community compositions were evaluated by calculating two ecological parameters: Shannon diversity (Fig. 3B) and Simpson index (Fig. 3C). Microbial diversity, richness and evenness were significantly decreased in the untreated SHR group relative to the P-SPI and Captopril groups. The P-SPI group had the highest gut microbial richness and evenness. To calculate distances between the bacteria communities in faecal samples from the three rat groups, we used weighted UniFrac to assess their relative relatedness and visualized it by performing a 2-D PCoA. There was a clear separation between the three clusters indicating three distinct gut environments (Fig. 3D). Also, BrayCurtis dissimilarity was used to analyze how different the gut bacteria communities of the three rat groups were from each other, and this was visualized in a dendrogram. The composition of the faecal microbial communities of the P-SPI group was distinct, while Captopril-treated rats had similar communities to those of untreated rats (Fig. 3E). At the phylum level, Firmicutes accounted for $82.3 \%$ of the entire OTUs identified in the faecal samples of untreated SHRs, while Bacteroidetes accounted for $8.2 \%$ (Fig. 4). When the rats were treated with Captopril, the levels of Firmicutes were reduced to $61.3 \%$, while the levels of Bacteroidetes increased to $25.3 \%$. P-SPI feeding, however, reduced Firmicutes populations in SHRs to $49.6 \%$ and increased Bacteroidetes populations to $46.6 \%$.

SHRs had low levels of Bacteroidia and diminished levels of Alphaproteobacteria, but they had high levels of Clostridia. After the administration of P-SPI, the levels of Bacteroidia and Alphaproteobacteria increased significantly, while the populations of Clostridia decreased (Fig. 5 and Supplementary Fig. 2). Also, treatment of SHRs with P-SPI significantly increased the levels of Bacteroidales, Rhodospirillales and Desulfovibrionales. However, the levels of Erysipelotrichales and Clostridiales were significantly decreased after P-SPI treatment (Fig. 6 and Supplementary Fig. 3). At the family level, P-SPI administration significantly increased the levels of Bacteroidaceae, Prevotellaceae and Christensenellaceae in SHRs. However, P-SPI treatment drastically decreased the populations of Peptostreptococcaceae, Erysipelotrichaceae and Streptococcaceae (Fig. 7 and Supplementary Fig. 4). At the genus level, P-SPI increased the levels of Christensenella, Bacteroides, Parabacteroides, Sporanaerobacter, Caloramator and Prevotella in SHRs, while it reduced the levels of Clostridium in SHRs (Fig. 8 and Supplementary Fig. 5). 

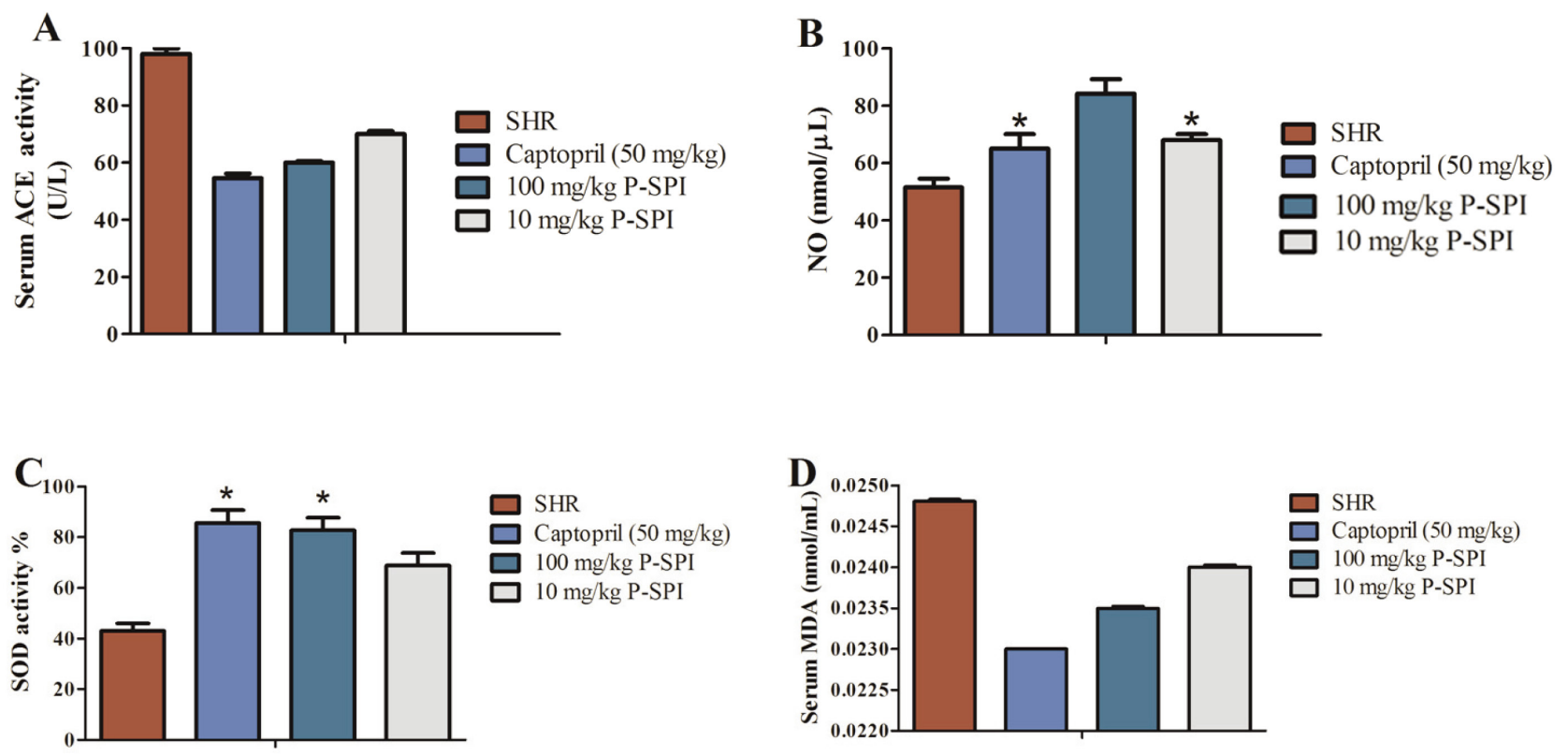

Fig. 2. Effects of P-SPI on serum ACE activity, SOD, NO and MDA levels. (A) ACE activity before and after treating hypertensive rats with P-SPI or Captopril compared to normotensive rats, (B) levels of NO release before and after P-SPI or Captopril treatment compared to normotensive rats, (C) SOD activity before and after treating hypertensive rats with P-SPI or Captopril compared to normotensive rats and (D) serum MDA levels in hypertensive rats before and after P-SPI treatment compared to untreated spontaneous hypertensive rats. Data points represent means $\pm \mathrm{SD}$. *Data points were not significantly different $(\mathrm{p}>0.05)$.
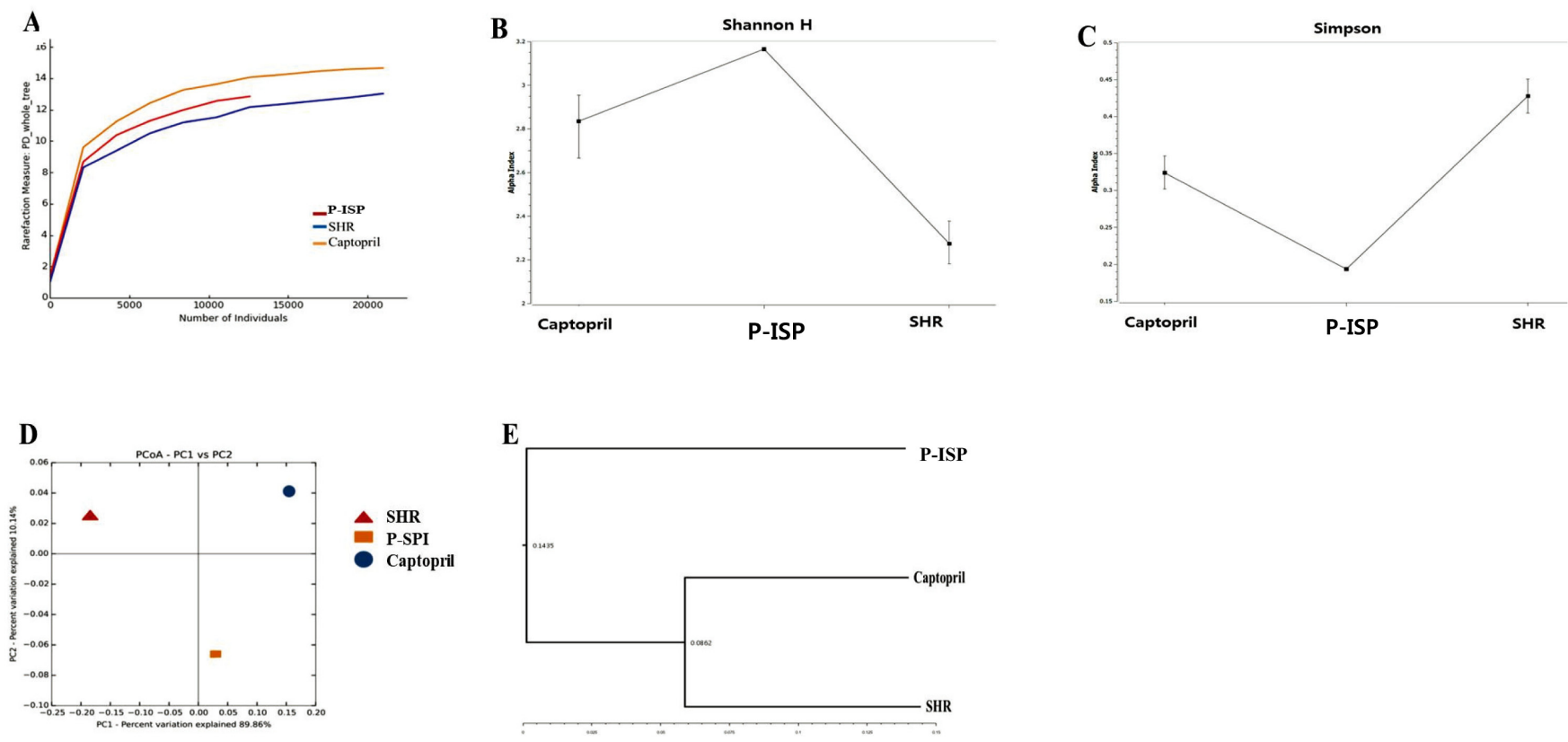

Fig. 3. Changes in the gut microbiota of rats before and after Captopril or P-SPI treatment. (A) Rarefaction curves for phylogenetic dispersion ( $\triangle \mathrm{PD}$ ), (B) Shannon index, (C) Simpson index, (D) weighted UniFrac 2D PCoA plots illustrating the distance between faecal microbial communities from the P-SPI, Captopril and spontaneous hypertensive rat groups and (E) cluster analysis of Bray-Curtis similarity indices of gut microbiota of the three rat groups.

\section{DISCUSSION}

Since hypertension is a key risk factor for cardiovascular disease and brain stroke, a reduction in blood pressure reduces the risk of these diseases [13]. Results from the present study showed a clear reduction in SBP and DBP when hypertensive rats were fed with P-SPI (Fig. 1 and Supplementary Fig. 1). In an earlier study, Shin et al. [21] reported a $32 \mathrm{mmHg}$ reduction in 

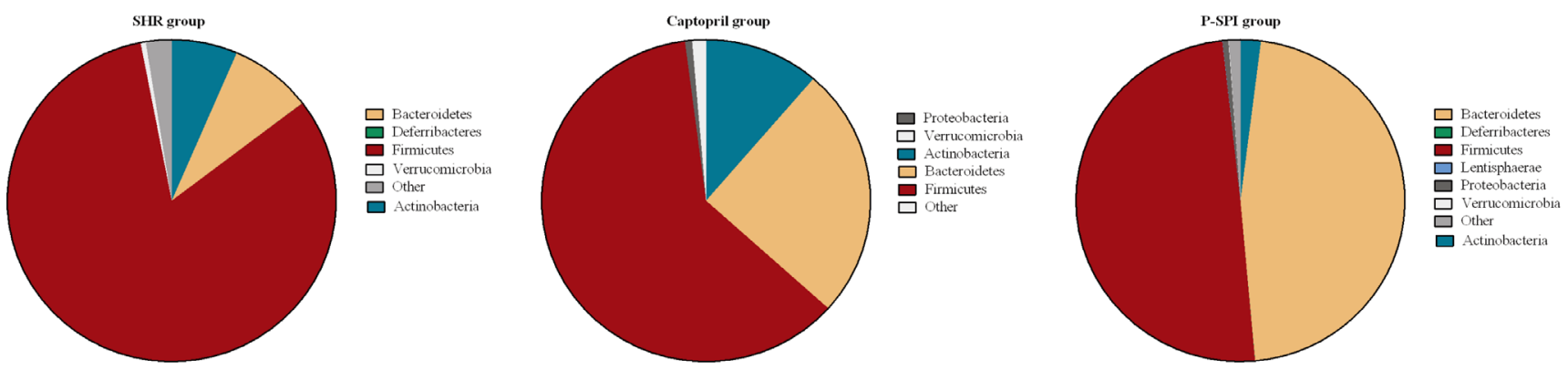

Fig. 4. The effect of P-SPI and Captopril administration on the major phyla of gut bacteria of rats. Fecal samples were collected from spontaneous hypertensive rats $(\mathrm{n}=5)$, the P-SPI group $(\mathrm{n}=5)$ and the Captopril group $(\mathrm{n}=5)$.
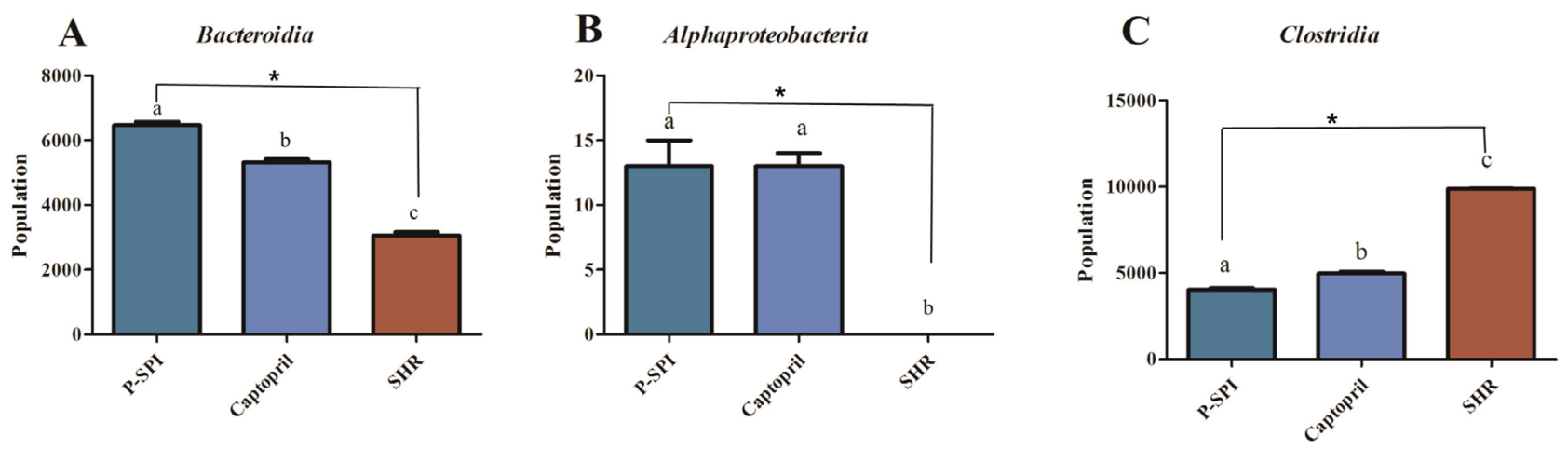

Fig. 5. Effects of P-SPI feeding on bacteria class. Bar graphs represent gut microbial classes with significant changes after rats were treated with P-SPI or Captopril.
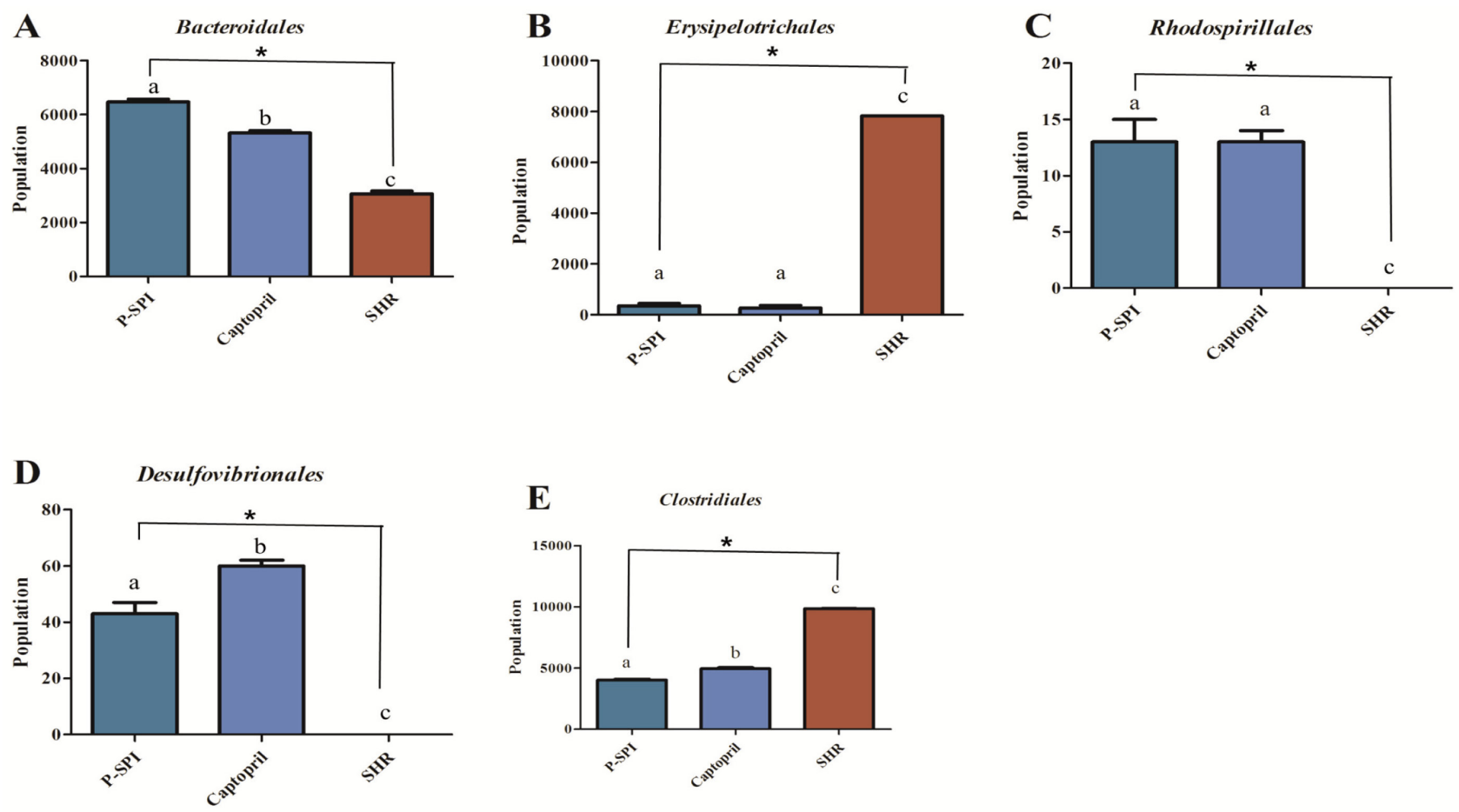

Fig. 6. Effects of P-SPI feeding on bacteria order. Bar graphs represent gut microbial orders with significant changes after rats were treated with P-SPI or Captopril. 

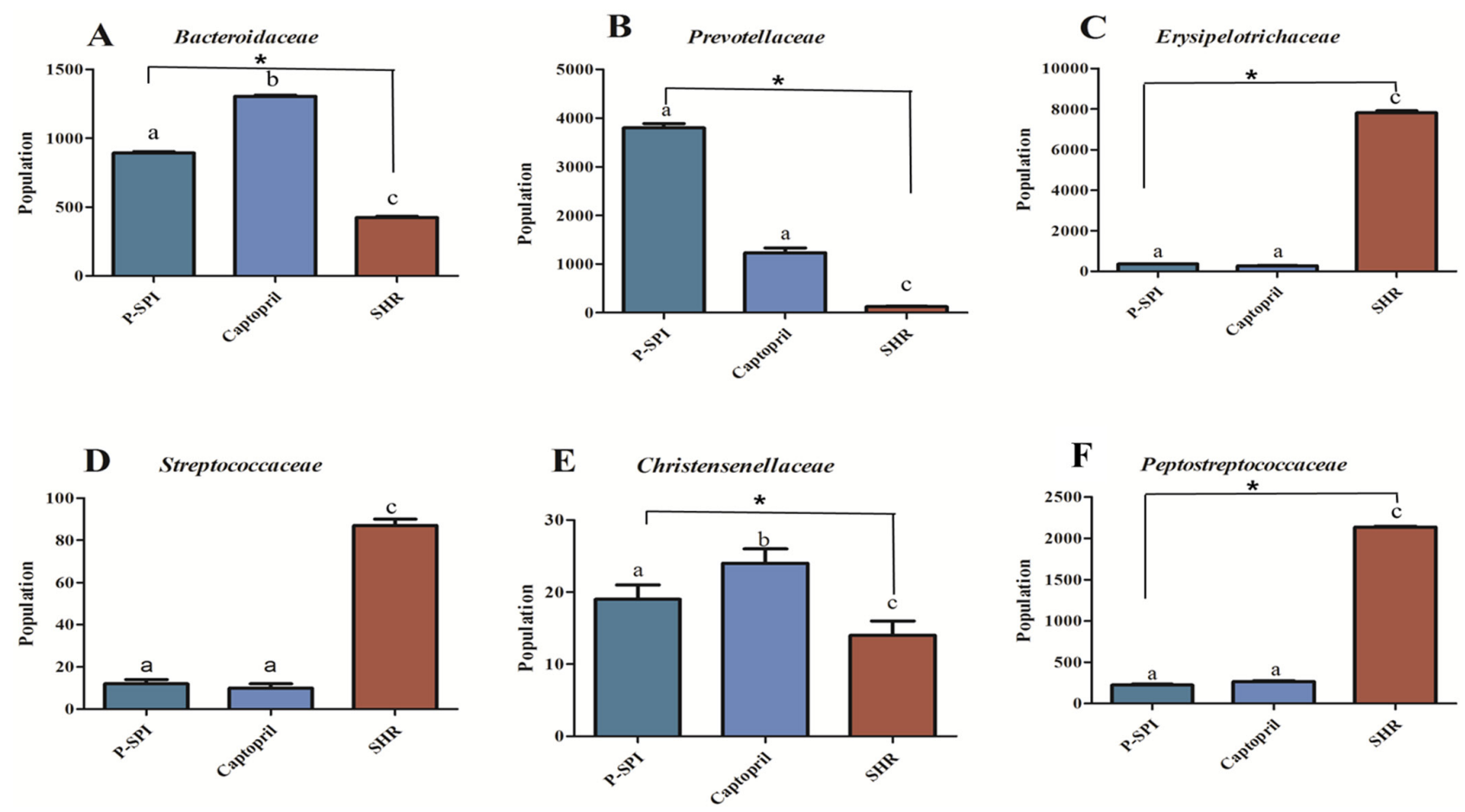

Fig. 7. Effects of P-SPI feeding on bacteria family. Bar graphs represent gut microbial families with significant changes after rats were treated with P-SPI or Captopril.

blood pressure after rats were injected with $5 \mathrm{mg} / \mathrm{kg}$ of a soybean tripeptide (HHL). The drastic reduction in blood pressure could have been influenced by the route of administration, as intravenous administration makes the peptides readily available in blood for transportation to target organs. In contrast, when peptides are orally administered (as in this study), they may be hydrolyzed and later absorbed. Unabsorbed peptides are then transported to the colon for gut microbial fermentation. All these factors could account for the differences in antihypertensive effects of peptides reported over the years. In this study, although the antihypertensive ability of Captopril (a standard antihypertensive drug) was relatively higher than that of P-SPI, the significance of P-SPI lies in the fact that it is relatively cheap and easy to produce. Moreover, food-derived antihypertensive peptides have been shown to have better tissue affinities and to be more slowly cleared from tissues [22]. The slow clearance would therefore enhance a slower rate of blood pressure increase even after the redrawal from the treatment.

In our earlier study, we reported how P-SPI strongly inhibited ACE activity in vitro and reduced high blood pressure in SHRs after long-term feeding (Supplementary Fig. 1) [15]. In this study, single oral doses of P-SPI also significantly lowered blood pressure in hypertensive rats and so we studied the mechanisms which might have led to the antihypertensive effect. It was observed that P-SPI consumption significantly decreased serum ACE activity. ACE is known to mediate the conversion of angiotensin I to angiotensin II (the rate-limiting step of the RAAS), so a decrease in its activity would eventually lower blood pressure [23]. Similar findings regarding the ability of ACE inhibition in the blood to reduce blood pressure have been reported in earlier studies [24, 25]. Since P-SPI significantly reduced ACE activity in circulating serum, it is likely that this mechanistic pathway is involved in its hypotensive effect.

Relative to the untreated SHRs, serum NO concentrations were significantly increased in P-SPI-fed rats in a dose-dependent manner. Nitric oxide plays a role in vasorelaxation and neutralizes superoxide radicals to prevent oxidative damage [26]. Earlier studies have shown that low NO bioavailability may result in the development of endothelial dysfunction and eventually cause high blood pressure [27]. Therefore, the ability of P-SPI to increase NO bioavailability may have played a role in reducing blood pressure by improving vasodilation in this study. Our findings agree with those of an earlier study that reported the ability of fermented milk to reduce hypertension by increasing NO production in rats [27]. Earlier studies have shown that antihypertensive products such as Captopril [28, 29] and some natural products [30] enhance enzymatic antioxidant levels and activities. In this study also, SOD activity was significantly improved after hypertensive rats were treated with Captopril or P-SPI (Fig. 2C). Interestingly, there was no significant difference between hypertensive rats that were treated with $100 \mathrm{mg} / \mathrm{kg}$ body weight of P-SPI and the Captopril-treated group. SODs are major antioxidant defense systems that reduce $\mathrm{O}_{2}{ }^{--}$in mammals, and they play important roles in the defense against the pathogenesis of hypertension [31]. A significant reduction in SOD activity increases myogenic tone, augments vasoconstrictor responses in response to serotonin and phenylephrine and impairs NO-mediated endothelium-dependent relaxation in both large arteries and microvessels [32]. Therefore, the ability of P-SPI to increase SOD activity in serum could have played a role in reducing high blood pressure in the hypertensive rats.

Recent studies have shown that an increase in biomarkers of lipid peroxidation in the blood is associated with hypertension in humans [33]. We therefore indirectly estimated the extent of 

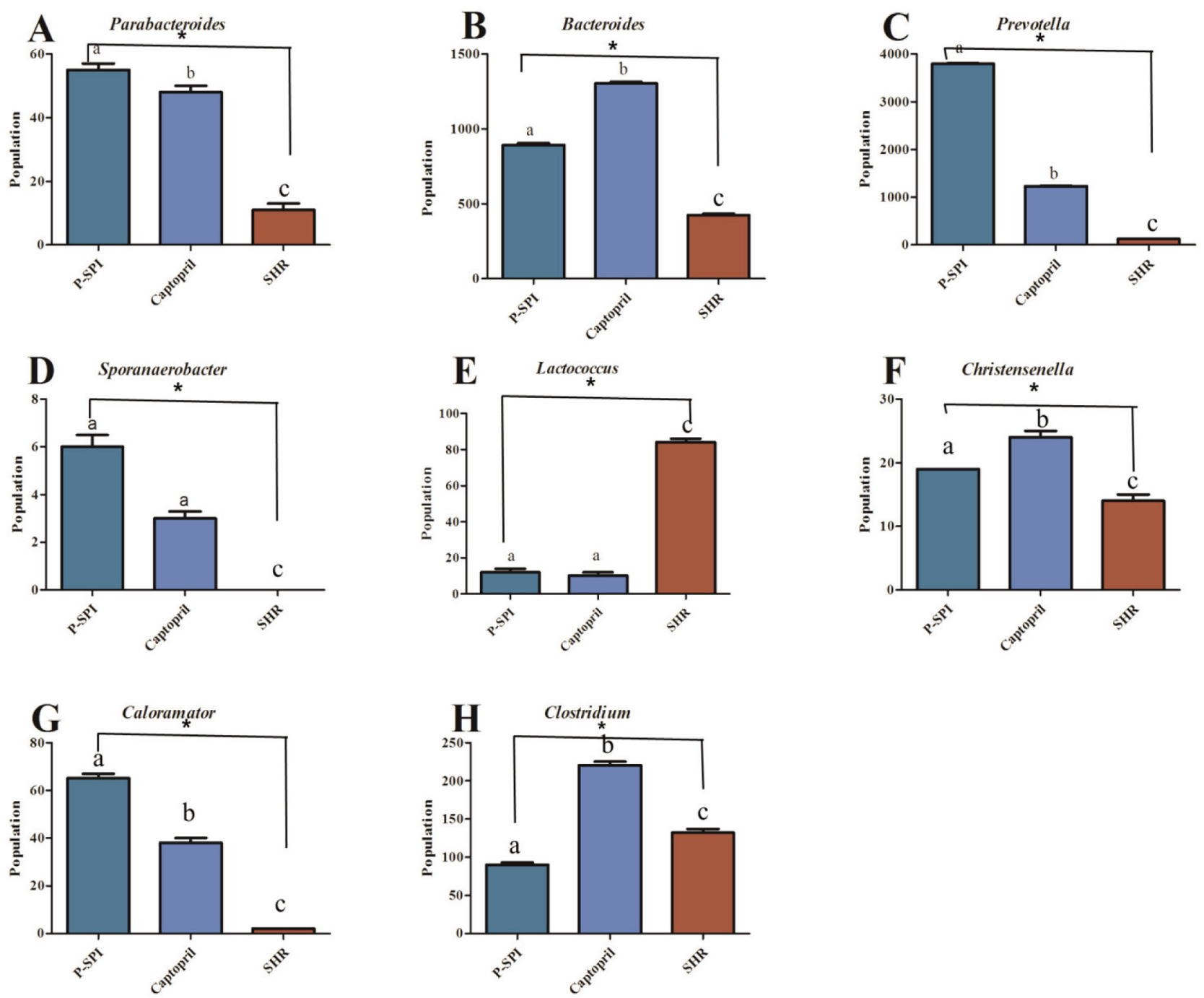

Fig 8. Effects of P-SPI feeding on bacteria genus. Bar graphs represent gut microbial genus with significant changes after rats were treated with P-SPI or Captopril.

lipid peroxidation by measuring the amounts of malondialdehyde in the serum of experimental animals. P-SPI reduced serum malondialdehyde levels in a dose-dependent manner, while the level of malondialdehyde remained high in hypertensive rats.

Since diets have important impacts on the gut microbiota, it is probable that apart from the absorption of low-molecular-weight P-SPI peptides into the circulation, which may eventually inhibit ACE activity in serum and in tissues [13, 22], unabsorbed peptides could influence the gut microbiota to contribute to the observed blood pressure-lowering effect. This idea is supported by the fact that hypertension has a strong association with dysbiosis of the gut microbiota and that modulating the gut microbes may reduce high blood pressure [34]. Our results show that the SHRs had reduced gut microbial evenness, richness and diversity, and this agrees with previous human studies that showed reduced gut microbial species richness, evenness and diversity in hypertensive patients [5]. The gut ecological evenness and richness of the rats were, however, improved after P-SPI was consumed for six weeks.

A key biomarker for hypertension is the Firmicutes/ Bacteroidetes ratio $[35,36]$, and this was dramatically increased in the faecal samples of the SHRs used in this study. The increase in Firmicutes/Bacteroidetes ratio was caused by a significant increase in the levels of Firmicutes and a drastic decrease in the levels of Bacteroidetes (Fig. 4). Feeding rats with P-SPI significantly decreased the levels of Firmicutes (F) while increasing the levels of Bacteroidetes (B). This implies that P-SPI has modulatory effect on the gut microbiota might have played a role in reducing blood pressure.

Recent reports have shown that several diseases that involve inflammatory processes are associated with reduced populations of Bacteroidia (propionate producers) [37] and Alphaproteobacteria in the gut [38]. Propionate is essential because it binds to receptors Olfr78, Gpr41 and Gpr43 to induce vasodilation of blood vessels and reduce high blood pressure $[39,40]$. In this study, feeding SHRs with P-SPI significantly increased the levels of Bacteroidia and Alphaproteobacteria, indicating the anti-inflammatory potential and consequent antihypertensive ability of P-SPI. Also, P-SPI increased Desulfovibrionales levels (Fig. 6C) in the SHR gut. These bacteria produce $\mathrm{H}_{2} \mathrm{~S}$ in the gut, which plays a critical role in arterial blood pressure regulation [41]. The populations 
of potential pathogenic bacteria such as Streptococcaceae and Erysipelotrichales were high in SHRs but were drastically reduced after P-SPI feeding. Bacteria genera such as Prevotella, Bacteroides and Christensenella, which are usually reduced in hypertensive patients [42], were significantly increased after SHRs were fed with P-SPI (Fig. 8).

P-SPI consumption therefore reduces hypertension and improves the gut microbiota of SHRs. Taken together, we have demonstrated the antihypertensive ability of P-SPI and some mechanisms that are involved in the blood pressure-reducing effect. Our results show that P-SPI reduces blood pressure by directly inhibiting serum ACE activity, improving NO production and enhancing antioxidation in a dose-dependent manner. Also, we have demonstrated how long-term feeding of P-SPI positively modulates the gut microbiota in SHRs and how these changes are associated with hypertension reduction. Since the rat gut metagenome is very similar to that of humans, P-SPI consumption may positively modulate the gut microbiota and reduce hypertension in humans. However, further studies about which microbial metabolites are produced after P-SPI consumption are warranted. Identifying such compounds would be helpful in understanding the molecular mechanism behind the antihypertensive effects of P-SPI.

\section{AUTHOR CONTRIBUTIONS}

The study was conceptualized by E.B-M.D. and D-H.O.; the methodology was designed by J-H.K. and E.B-M.D.; the experiments were carried out by F.K.O., H.A. and K.B.K.; the formal analysis was done by E.B-M.D. and R.C.; the original draft of the manuscript was prepared by E.B-M.D.; and the manuscript was reviewed and edited by D-H.O. and B.H.L.

\section{CONFLICT OF INTEREST}

The authors declare no conflict of interest.

\section{ACKNOWLEDGEMENT}

This study was financially supported by IPET Korea No. 119014032 SB010 (Korea Institute of Planning and Evaluation for Technology in Food, Agriculture, Forestry and Fisheries).

\section{REFERENCES}

1. Mendizábal Y, Llorens S, Nava E. 2013. Hypertension in metabolic syndrome: vascular pathophysiology. Int J Hypertens 2013: 230868. [Medline] [CrossRef]

2. Dinh QN, Drummond GR, Sobey CG, Chrissobolis S. 2014. Roles of inflammation, oxidative stress, and vascular dysfunction in hypertension. BioMed Res Int 2014: 406960. [Medline] [CrossRef]

3. Singh MV, Chapleau MW, Harwani SC, Abboud FM. 2014. The immune system and hypertension. Immunol Res 59: 243-253. [Medline] [CrossRef]

4. Bleakley S, Hayes M, O' Shea N, Gallagher E, Lafarga T. 2017. Predicted release and analysis of novel ACE-I, renin, and DPP-IV inhibitory peptides from common oat (Avena sativa) protein hydrolysates using in silico analysis. Foods 6: 108. [Medline] [CrossRef]

5. Li J, Zhao F, Wang Y, Chen J, Tao J, Tian G, Wu S, Liu W, Cui Q, Geng B, Zhang W, Weldon R, Auguste K, Yang L, Liu X, Chen L, Yang X, Zhu B, Cai J. 2017. Gut microbiota dysbiosis contributes to the development of hypertension. Microbiome 5: 14 [CrossRef]. [Medline]

6. Daliri EBM, Tango CN, Lee BH, Oh DH. 2018. Human microbiome restoration and safety. Int J Med Microbiol 308: 487-497. [Medline] [CrossRef]

7. De Almeida CV, de Camargo MR, Russo E, Amedei A. 2019. Role of diet and gut microbiota on colorectal cancer immunomodulation. World J Gastroenterol 25: 151-162. [Medline] [CrossRef]
8. Gamallat Y, Ren XM, Meyiah A, Li MQ, Ren XX, Jamalat Y, Song SY, Xie LH, Ahmad B, Shopit A, Mousa H, Ma YF, Xin Y, Ding DP. 2019. The immune-modulation and gut microbiome structure modification associated with long-term dietary supplementation of Lactobacillus rhamnosus using 16S rRNA sequencing analysis. J Funct Foods 53: 227-236. [CrossRef]

9. Sun S, Lulla A, Sioda M, Winglee K, Wu MC, Jacobs DR Jr, Shikany JM, Lloyd-Jones DM, Launer LJ, Fodor AA, Meyer KA. 2019. Gut microbiota composition and blood pressure. Hypertension 73: 998-1006. [Medline] [CrossRef]

10. Yan Q, Gu Y, Li X, Yang W, Jia L, Chen C, Han X, Huang Y, Zhao L, Li P, Fang Z, Zhou J, Guan X, Ding Y, Wang S, Khan M, Xin Y, Li S, Ma Y. 2017. Alterations of the gut microbiome in hypertension. Front Cell Infect Microbiol 7: 381. [Medline] [CrossRef]

11. Matsuyama M, Morrison M, Cao KL, Pruilh S, Davies PSW, Wall C, Lovell A, Hill RJ. 2019. Dietary intake influences gut microbiota development of healthy Australian children from the age of one to two years. Sci Rep 9: 12476. [Medline] [CrossRef]

12. Zhu Y, Lin X, Zhao F, Shi X, Li H, Li Y, Zhu W, Xu X, Li C, Zhou G. 2015. Meat, dairy and plant proteins alter bacterial composition of rat gut bacteria. Sci Rep 5: 15220 . [Medline] [CrossRef]

13. Daliri EBM, Lee BH, Oh DH. 2018. Current trends and perspectives of bioactive peptides. Crit Rev Food Sci Nutr 58: 2273-2284. [Medline] [CrossRef]

14. Ciau-Solís NA, Acevedo-Fernández JJ, Betancur-Ancona D. 2018. In vitro reninangiotensin system inhibition and in vivo antihypertensive activity of peptide fractions from lima bean (Phaseolus lunatus L.). J Sci Food Agric 98: 781-786. [Medline] [CrossRef]

15. Daliri EBM, Ofosu FK, Chelliah R, Park MH, Kim JH, Oh DH. 2019. Development of a soy protein hydrolysate with an antihypertensive effect. Int J Mol Sci 20: 1496. [Medline] [CrossRef]

16. Cushman DW, Cheung HS. 1971. Spectrophotometric assay and properties of the angiotensin-converting enzyme of rabbit lung. Biochem Pharmacol 20: 1637-1648. [Medline] [CrossRef]

17. Robertson CE, Harris JK, Wagner BD, Granger D, Browne K, Tatem B, Feazel LM, Park K, Pace NR, Frank DN. 2013. Explicet: graphical user interface software for metadata-driven management, analysis and visualization of microbiome data. Bioinformatics 29: 3100-3101. [Medline] [CrossRef]

18. Yang H, Bai W, Gao L, Jiang J, Tang Y, Niu Y, Lin H, Li L. 2018. Mangiferin alleviates hypertension induced by hyperuricemia via increasing nitric oxide releases. J Pharmacol Sci 137: 154-161. [Medline] [CrossRef]

19. Gómez-Marcos MA, Blázquez-Medela AM, Gamella-Pozuelo L, Recio-Rodriguez JI, García-Ortiz L, Martínez-Salgado C. 2016. Serum superoxide dismutase is associated with vascular structure and function in hypertensive and diabetic patients. Oxid Med Cell Longev 2016: 9124676. [Medline] [CrossRef]

20. Pawluk H, Pawluk R, Robaczewska J, Kędziora-Kornatowska K, Kẹdziora J. 2017. Biomarkers of antioxidant status and lipid peroxidation in elderly patients with hypertension. Redox Rep 22: 542-546. [Medline] [CrossRef]

21. Shin ZI, Yu R, Park SA, Chung DK, Ahn CW, Nam HS, Kim KS, Lee HJ. 2001. His-His-Leu, an angiotensin I converting enzyme inhibitory peptide derived from Korean soybean paste, exerts antihypertensive activity in vivo. J Agric Food Chem 49: 3004-3009. [Medline] [CrossRef]

22. Koyama M, Hattori S, Amano Y, Watanabe M, Nakamura K. 2014. Blood pressurelowering peptides from neo-fermented buckwheat sprouts: a new approach to estimating ACE-inhibitory activity. PLoS One 9: e105802. [Medline] [CrossRef]

23. Majumder K, Wu J. 2014. Molecular targets of antihypertensive peptides: understanding the mechanisms of action based on the pathophysiology of hypertension. Int J Mol Sci 16: 256-283. [Medline] [CrossRef]

24. Fernández-Musoles R, Manzanares P, Burguete MC, Alborch E, Salom JB 2013. In vivo angiotensin I-converting enzyme inhibition by long-term intake of antihypertensive lactoferrin hydrolysate in spontaneously hypertensive rats. Food Res Int 54: 627-632. [CrossRef]

25. Ruiz-Giménez P, Ibáñez A, Salom JB, Marcos JF, López-Díez JJ, Vallés S, Torregrosa G, Alborch E, Manzanares P. 2010. Antihypertensive properties of lactoferricin B-derived peptides. J Agric Food Chem 58: 6721-6727. [Medline] [CrossRef]

26. Laurindo FR, Liberman M, Fernandes DC, Leite PF. 2018. Endothelium-dependen vasodilation: nitric oxide and other mediators. In: Endothelium and Cardiovascular Diseases, Elsevier, pp. 97-113.

27. Kim SM, Park S, Choue R. 2010. Effects of fermented milk peptides supplement on blood pressure and vascular function in spontaneously hypertensive rats. Food Sci Biotechnol 19: 1409-1413. [CrossRef]

28. Vahidirad M, Arab-Nozari M, Mohammadi H, Zamani E, Shaki F. 2018. Protective effect of captopril against diazinon induced nephrotoxicity and neurotoxicity via inhibition of ROS-NO pathway. Drug Chem Toxicol 41: 287-293. [Medline] [CrossRef]

29. El-Ashmawy NE, Khedr NF, El-Bahrawy HA, Hamada OB. 2018. Anti-inflammatory and antioxidant effects of captopril compared to methylprednisolone in L-Arginineinduced acute pancreatitis. Dig Dis Sci 63: 1497-1505. [Medline] [CrossRef]

30. He R, Wang Y, Yang Y, Wang Z, Ju X, Yuan J. 2019. Rapeseed protein-derived ACE inhibitory peptides LY, RALP and GHS show antioxidant and anti-inflammatory effects on spontaneously hypertensive rats. J Funct Foods 55: 211-219. [CrossRef] 
31. Fukai T, Ushio-Fukai M. 2011. Superoxide dismutases: role in redox signaling, vascular function, and diseases. Antioxid Redox Signal 15: 1583-1606. [Medline] [CrossRef]

32. Didion SP, Ryan MJ, Didion LA, Fegan PE, Sigmund CD, Faraci FM. 2002. Increased superoxide and vascular dysfunction in CuZnSOD-deficient mice. Circ Res 91: 938-944. [Medline] [CrossRef]

33. Yavuzer H, Yavuzer S, Cengiz M, Erman H, Doventas A, Balci H, Erdincler DS, Uzun H. 2016. Biomarkers of lipid peroxidation related to hypertension in aging. Hypertens Res 39: 342-348. [Medline] [CrossRef]

34. Yang T, Santisteban MM, Rodriguez V, Li E, Ahmari N, Carvajal JM, Zadeh M, Gong M, Qi Y, Zubcevic J, Sahay B, Pepine CJ, Raizada MK, Mohamadzadeh M. 2015. Gut dysbiosis is linked to hypertension. Hypertension 65: 1331-1340. [Medline] [CrossRef]

35. Jose PA, Raj D. 2015. Gut microbiota in hypertension. Curr Opin Nephrol Hypertens 24: 403-409. [Medline] [CrossRef]

36. Mell B, Jala VR, Mathew AV, Byun J, Waghulde H, Zhang Y, Haribabu B, VijayKumar M, Pennathur S, Joe B. 2015. Evidence for a link between gut microbiota and hypertension in the Dahl rat. Physiol Genomics 47: 187-197 [CrossRef]. [Medline]

37. Bauer E, Thiele I. 2018. From metagenomic data to personalized in silico microbiotas: predicting dietary supplements for Crohn's disease. NPJ Syst Biol Appl 4: 27.
[Medline] [CrossRef]

38. Everard A, Lazarevic V, Derrien M, Girard M, Muccioli GG, Neyrinck AM, Possemiers S, Van Holle A, François P, de Vos WM, Delzenne NM, Schrenzel J, Cani PD. 2011. Responses of gut microbiota and glucose and lipid metabolism to prebiotics in genetic obese and diet-induced leptin-resistant mice. Diabetes 60: 2775-2786. [Medline] [CrossRef]

39. Pluznick JL, Protzko RJ, Gevorgyan H, Peterlin Z, Sipos A, Han J, Brunet I, Wan LX, Rey F, Wang T, Firestein SJ, Yanagisawa M, Gordon JI, Eichmann A, Peti-Peterdi J, Caplan MJ. 2013. Olfactory receptor responding to gut microbiota-derived signals plays a role in renin secretion and blood pressure regulation. Proc Natl Acad Sci USA 110: 4410-4415. [Medline] [CrossRef]

40. Natarajan N, Hori D, Flavahan S, Steppan J, Flavahan NA, Berkowitz DE, Pluznick JL 2016. Microbial short chain fatty acid metabolites lower blood pressure via endothelial G protein-coupled receptor 41. Physiol Genomics 48: 826-834. [Medline] [CrossRef]

41. Tomasova L, Dobrowolski L, Jurkowska H, Wróbel M, Huc T, Ondrias K, Ostaszewski R, Ufnal M. 2016. Intracolonic hydrogen sulfide lowers blood pressure in rats. Nitric Oxide 60: 50-58. [Medline] [CrossRef]

42. Dan X, Mushi Z, Baili W, Han L, Enqi W, Huanhu Z, Shuchun L. 2019. Differential analysis of hypertension-associated intestinal microbiota. Int J Med Sci 16: 872-881. [Medline] [CrossRef] 